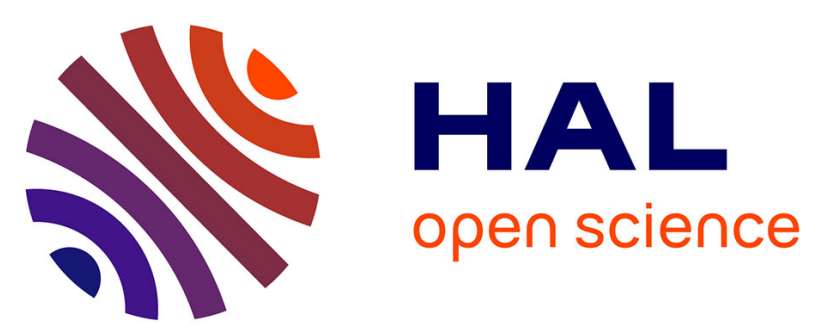

\title{
Epitaxial La0.7Sr0.3MnO3 thin films grown on SrTiO3 buffered silicon substrates by reactive molecular-beam epitaxy
}

\author{
Laurence Méchin, C. Adamo, Sheng Wu, Bruno Guillet, Sylvain Lebargy,
} Cédric Fur, Jean-Marc Routoure, Sylvana Mercone, Mohamed Belmeguenai, D.G. Schlom

\section{To cite this version:}

Laurence Méchin, C. Adamo, Sheng Wu, Bruno Guillet, Sylvain Lebargy, et al.. Epitaxial La0.7Sr0.3MnO3 thin films grown on SrTiO3 buffered silicon substrates by reactive molecular-beam epitaxy. physica status solidi (a), 2012, 209 (6), pp.1090-1095. hal-00976339

\section{HAL Id: hal-00976339 \\ https://hal.science/hal-00976339}

Submitted on 9 Apr 2014

HAL is a multi-disciplinary open access archive for the deposit and dissemination of scientific research documents, whether they are published or not. The documents may come from teaching and research institutions in France or abroad, or from public or private research centers.
L'archive ouverte pluridisciplinaire HAL, est destinée au dépôt et à la diffusion de documents scientifiques de niveau recherche, publiés ou non, émanant des établissements d'enseignement et de recherche français ou étrangers, des laboratoires publics ou privés. 


\title{
Epitaxial $\mathrm{La}_{0.7} \mathrm{Sr}_{0.3} \mathrm{MnO}_{3}$ thin films grown on $\mathrm{SrTiO}_{3}$ buffered silicon substrates by reactive molecular-beam epitaxy
}

\author{
L. Méchin ${ }^{*, 1}$, C. Adamo*,2, S. Wu', B. Guillet', S. Lebargy', C. Fur', J.-M. Routoure', S. Mercone', \\ M. Belmeguenai ${ }^{3}$, and D. G. Schlom ${ }^{2,4}$ \\ ${ }^{1}$ GREYC (UMR 6072), CNRS - ENSICAEN, Université de Caen Basse-Normandie, 6 boulevard Maréchal Juin, 14050 Caen Cedex, \\ France \\ ${ }^{2}$ Department of Materials Science and Engineering, Cornell University, Ithaca, New York 14853-1501, USA \\ ${ }^{3}$ LSPM (UPR 3407), CNRS, Université Paris 13, 99 avenue Jean-Baptiste Clément, 93430 Villetaneuse, France \\ ${ }^{4}$ Kavli Institute at Cornell for Nanoscale Science, Ithaca, New York 14853, USA
}

Keywords epitaxy, low-frequency noise, oxides

*Corresponding author: e-mail laurence.mechin@ensicaen.fr, Phone: +332314526 92, Fax: +33231452698

**e-mail ca259@cornell.edu

$\mathrm{La}_{0.7} \mathrm{Sr}_{0.3} \mathrm{MnO}_{3}$ (LSMO) thin films (with a thickness of 10, 20, 60, 75, and $100 \mathrm{~nm}$ ) were grown on $\mathrm{SrTiO}_{3}$ (STO)-buffered silicon (001) substrates by reactive molecular-beam epitaxy. Xray diffraction (XRD) revealed the heterostructures to be fully epitaxial with orientation relationship (001) LSMO || (001) STO || (001) Si and [100] LSMO || [100] STO || [110] Si. Root mean square roughness was about $0.5 \mathrm{~nm}$ as measured by atomic force microscopy (AFM) for films of $10-75 \mathrm{~nm}$ thicknesses, and about $1 \mathrm{~nm}$ for the $100 \mathrm{~nm}$ thick LSMO film.
Normalized Hooge parameters in the $(0.95 \pm 0.25) \times 10^{-30}$ $(3.41 \pm 0.71) \times 10^{-30} \mathrm{~m}^{3}$ range were measured at $300 \mathrm{~K}$, which are comparable to the noise level typically measured in the best LSMO films on (001) STO substrates. Overall these very low noise LSMO films with thicknesses in the $10-100 \mathrm{~nm}$ range grown on STO/Si showed properties rivaling those of LSMO films deposited on (001) STO single crystal substrates, thus demonstrating their potential use for LSMO-based devices on silicon substrates.
1 Introduction Oxide perovskites are in demand for industrial applications as a result of their diverse physical properties $[1,2]$. In particular the colossal magnetoresistance observed in manganite compounds has been actively studied in view of its possible applications to innovative magnetic devices $[3,4]$. It is desirable to grow epitaxial oxide thin films on silicon in order to integrate them with Si-based devices [5]. Such integration involves several challenges including the removal of the amorphous $\mathrm{SiO}_{2}$ layer naturally present at the silicon surface, the large difference in thermal expansion coefficient between $\mathrm{Si}$ and oxides, and structural compatibility.

During the past years, many materials have been considered as buffer layer for growing epitaxial $\mathrm{La}_{0.7} \mathrm{Sr}_{0.3} \mathrm{MnO}_{3}$ (LSMO) thin films on silicon [6-11]. Polycrystalline LSMO films with a metal-to-insulator transition temperature $T_{\mathrm{MI}}$ of $225 \mathrm{~K}$ are generally obtained if grown on silicon covered by the native amorphous $\mathrm{SiO}_{x}$ layer [6]. Among possible buffer layer materials, $\mathrm{SrTiO}_{3}$ perovskite with a cubic unit cell of $0.3905 \mathrm{~nm}$ is widely used for the epitaxial integration of functional oxides on silicon. Significant progress has been made in the recent years. The work of McKee et al. [12] demonstrated the growth of high quality epitaxial STO films on Si (001) substrates by molecular-beam epitaxy, paving the way to many other related work involving the epitaxial growth of STO on silicon [13-19]. Polycrystalline LSMO films grown on STO/ Si by pulsed laser deposition (PLD) [20] or by sputtering [21] have been reported. Textured and oriented LSMO/STO/Si films were grown by PLD on STO buffered-Si with the STO layer showing both (110) and (001) orientations [22]. Moreover, Pradhan et al. [10] reported ferromagnetic temperature transitions $T_{\mathrm{C}}$ of 320 and $180 \mathrm{~K}$ for 55 and $20 \mathrm{~nm}$ LSMO thick films on STO/Si, respectively. Atomic 
force microscopy (AFM) data measured in $2 \mu \mathrm{m} \times 2 \mu \mathrm{m}$ images of the same 55 and $20 \mathrm{~nm}$ thick films showed a root mean square roughness of 2 and $1 \mathrm{~nm}$, respectively.

In this paper, an STO layer followed by an LSMO layer were grown on $\mathrm{Si}(001)$ by reactive molecular-beam epitaxy. We investigated the structural, topological, magnetic, electrical resistive, and low-frequency noise properties of $10-100 \mathrm{~nm}$ thick LSMO thin films deposited on STO/Si. Section 2 describes the conditions of film preparation, their structural and surface morphology properties. Magnetization and electrical resistivity of unpatterned films versus temperature are presented in Section 3. Section 4 is devoted to electrical low-frequency noise measurements, which is well accepted as a much more sensitive indication of the quality of materials or devices than static properties such as resistivity [23]. We present some results performed at $300 \mathrm{~K}$, and analyzed within the framework of the semi-empirical Hooge relation [24]. The latter routinely enables the evaluation of noise level in materials of different compositions, sizes, and in different bias conditions.

2 Sample preparation, structural, and surface morphology We grew epitaxial STO thin films on (001) Si by reactive molecular-beam epitaxy. The growth was

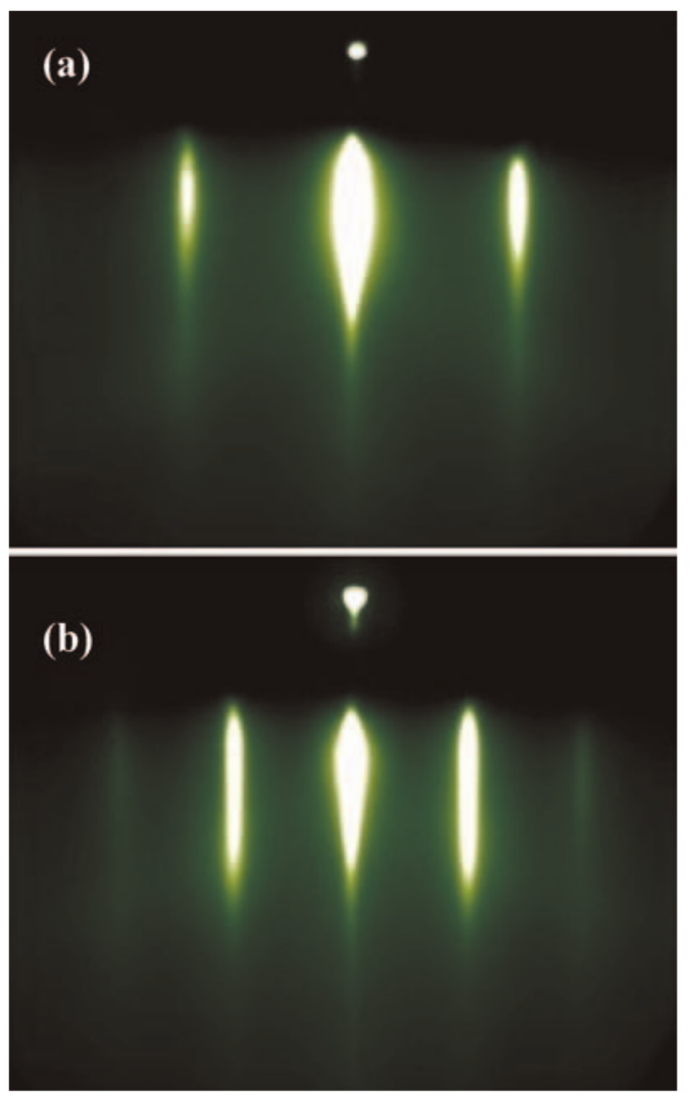

Figure 1 (online color at: www.pss-a.com) RHEED patterns at the end of the growth of a $(60 \mathrm{~nm}) \mathrm{LSMO} /(20 \mathrm{~nm}) \mathrm{STO} / \mathrm{Si}$ heterostructure. (a) RHEED image along the [100] azimuth of LSMO. (b) RHEED image along the [110] azimuth of LSMO. monitored by reflection high-energy electron diffraction (RHEED). For the $20 \mathrm{~nm}$ thick STO buffer layers, we used the same growth process reported previously $[18,25]$. Following the growth of the STO buffer layer, LSMO thin films with different thicknesses $(10-100 \mathrm{~nm})$ were deposited on top using a codeposition technique in which strontium, manganese, and lanthanum were simultaneously evaporated from effusion cells in the presence of distilled ozone. The fluxes of the constituent elements were measured using a quartz crystal monitor. The LSMO film was grown at a substrate temperature of $670^{\circ} \mathrm{C}$ in a distilled ozone background pressure of $5 \times 10^{-7}$ Torr [25]. The RHEED pattern at the completion of the $60 \mathrm{~nm}$ thick LSMO layer completing the LSMO/STO/Si heterostructure is shown in Fig. 1.

$\mathrm{X}$-ray diffraction (XRD) and AFM in tapping mode were used to investigate the structural and morphological properties of the samples. Figure 2 shows the XRD patterns in the $\theta-2 \theta$ configuration of the $10,20,60,75$, and $100 \mathrm{~nm}$ thick LSMO/STO/Si heterostructures.

Rocking curves in $\omega$ were measured for all the heterostructures. The full width at half maximum (FWHM) values around the (002) peaks of the rocking curve of STO and LSMO are reported in Table 1 . They were in the $0.22^{\circ}-$ $0.31^{\circ}$ and $0.18^{\circ}-0.33^{\circ}$ ranges, respectively, which are among lower reported values for epitaxial oxide films grown on silicon substrates. A pole figure of the 101 peak of the $60 \mathrm{~nm}$

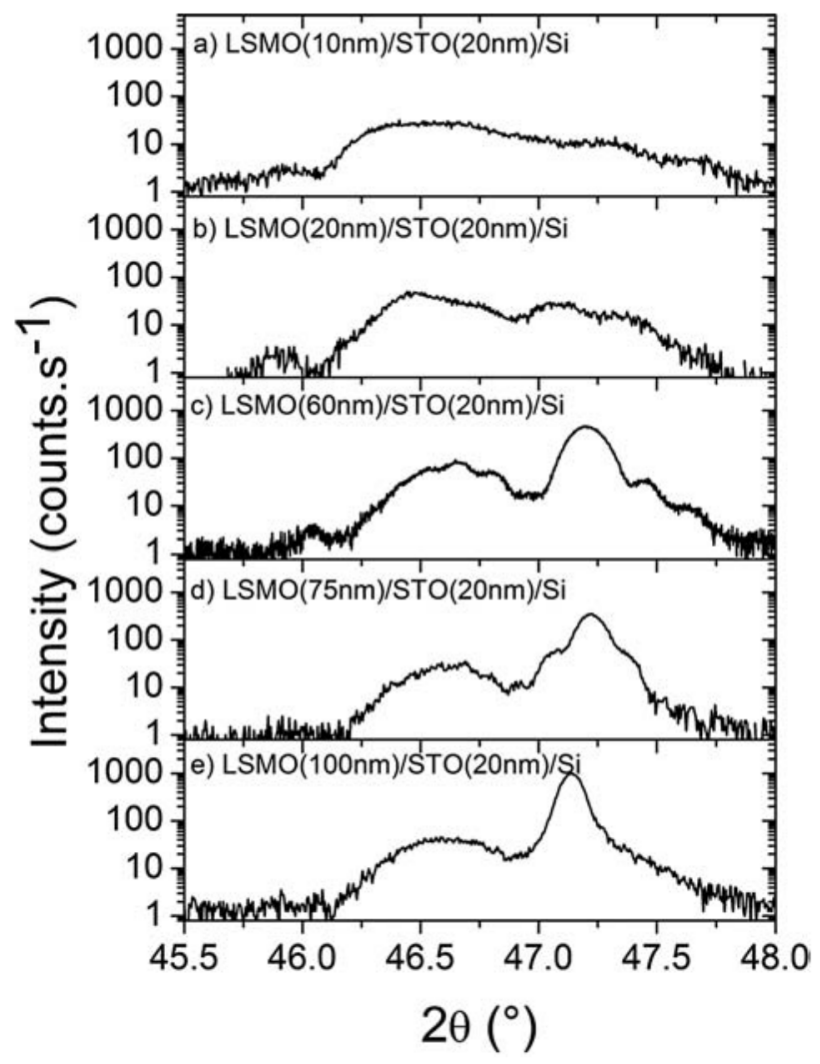

Figure 2 XRD patterns in the $\theta-2 \theta$ configuration of the (a) $10 \mathrm{~nm}$ thick; (b) $20 \mathrm{~nm}$ thick; (c) $60 \mathrm{~nm}$ thick; (d) $75 \mathrm{~nm}$ thick; (e) $100 \mathrm{~nm}$ thick LSMO films on STO/Si. 
Table 1 Summary of the structural, surface morphological, magnetic, and electrical properties of all the 10-100 nm thick LSMO/STO/Si films.

\begin{tabular}{|c|c|c|c|c|c|c|c|}
\hline $\begin{array}{l}\text { LSMO } \\
\text { thickness } \\
(\mathrm{nm})\end{array}$ & $\begin{array}{l}\text { FWHM } \\
\text { STO(002) } \\
\left({ }^{\circ}\right)\end{array}$ & $\begin{array}{l}\text { FWHM } \\
\text { LSMO(002) } \\
\left({ }^{\circ}\right)\end{array}$ & $\begin{array}{l}\text { rms } \\
\text { roughness } \\
(\mathrm{nm})\end{array}$ & $\begin{array}{l}\rho \text { at } \\
300 \mathrm{~K} \\
\left(10^{-5} \Omega \mathrm{m}\right)\end{array}$ & $\begin{array}{l}T_{\mathrm{C}} \\
(\mathrm{K})\end{array}$ & $\begin{array}{l}4 \pi M_{\mathrm{s}} \\
\text { at } 294 \mathrm{~K} \\
(\mathrm{kOe})\end{array}$ & $\begin{array}{l}\alpha_{\mathrm{H}} / n \\
\text { at } 300 \mathrm{~K} \\
\left(10^{-30} \mathrm{~m}^{3}\right)\end{array}$ \\
\hline 10 & 0.31 & 0.33 & 0.59 & 3.8 & 320 & 2.40 & $3.41 \pm 0.71$ \\
\hline 20 & 0.27 & 0.29 & 0.42 & 2.6 & 330 & 2.85 & $1.62 \pm 0.32$ \\
\hline 60 & 0.26 & 0.22 & 0.50 & 2.8 & 330 & 2.80 & $0.95 \pm 0.25$ \\
\hline 75 & 0.22 & 0.18 & 0.57 & 2.4 & 330 & 2.84 & $1.73 \pm 0.48$ \\
\hline 100 & 0.22 & 0.26 & 0.96 & 1.4 & 345 & 4.00 & $2.75 \pm 0.58$ \\
\hline
\end{tabular}

FWHM STO(002) and FWHM LSMO(002) are the FWHM values of the (002) peaks in an $\omega$-scan configuration for STO and LSMO, respectively; rms roughness is the root mean square roughness measured in $1 \mu \mathrm{m} \times 1 \mu \mathrm{m}$ AFMimages; $\rho$ at $300 \mathrm{~K}$ is the electrical resistivity at $300 \mathrm{~K}$; $T_{\mathrm{C}}$ is the Curie temperature; $4 \pi M_{\mathrm{s}}$ is the saturated magnetization at $294 \mathrm{~K} ; \alpha_{\mathrm{H}} / n$ at $300 \mathrm{~K}$ is the normalized Hooge parameter at $300 \mathrm{~K}$.

thick LSMO/STO/Si heterostructure showed that the heterostructure was epitaxial with an orientation relationship of (001) LSMO || (001) STO || (001) Si and [100] LSMO \| [100] STO ||$[110]$ Si.

Roughness was measured by AFM in tapping mode. As shown in the $1 \mu \mathrm{m} \times 1 \mu \mathrm{m}$ images of Fig. 3 very smooth films were obtained. The root mean square roughness measured in the $1 \mu \mathrm{m} \times 1 \mu \mathrm{m}$ images was about $0.5 \mathrm{~nm}$ for films of $10-75 \mathrm{~nm}$ thicknesses, and about $1 \mathrm{~nm}$ for the $100 \mathrm{~nm}$ thick LSMO film, as reported in Table 1. Again, these values are the lowest values reported in the literature for manganites on silicon substrates $[10,26]$.

\section{Magnetization and resistivity of unpatterned} films versus temperature Magnetization was measured by a superconducting quantum interference device (SQUID) a) $10 \mathrm{~nm}$

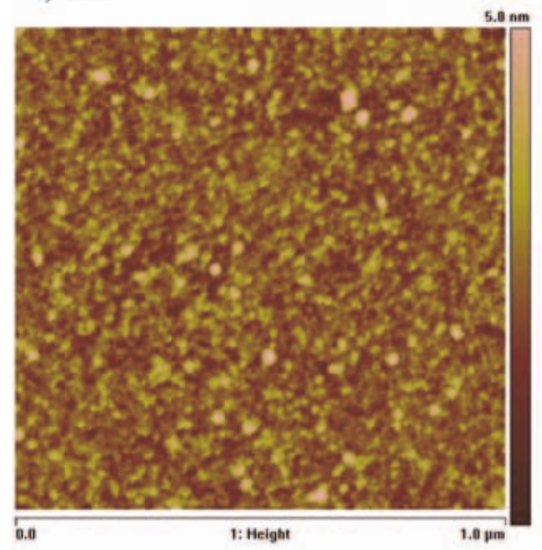

d) $75 \mathrm{~nm}$

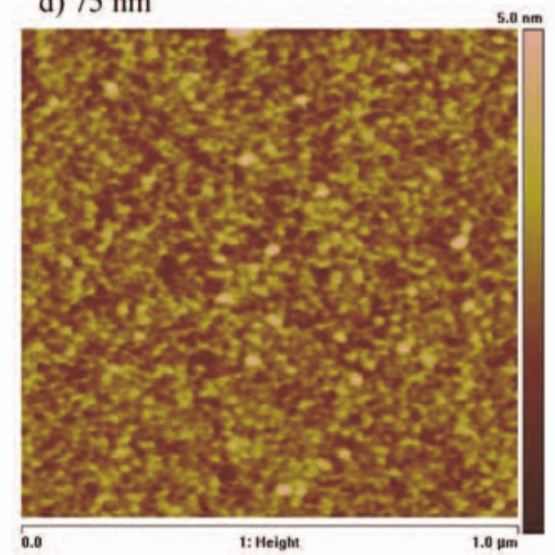

b) $20 \mathrm{~nm}$

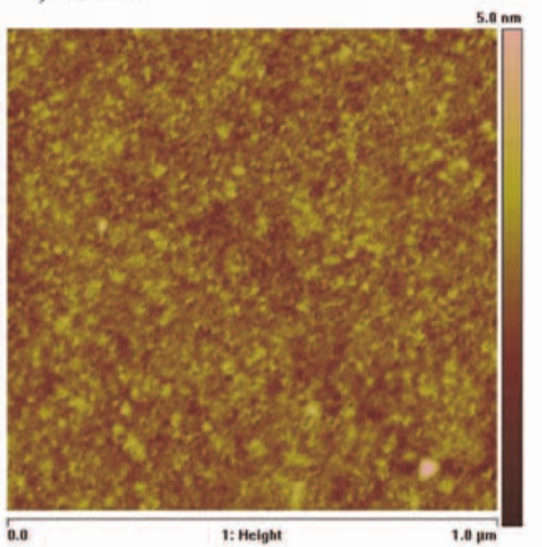

c) $60 \mathrm{~nm}$

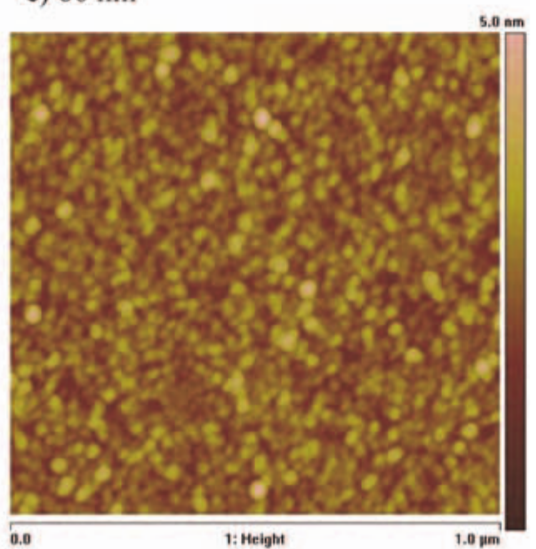

e) $100 \mathrm{~nm}$

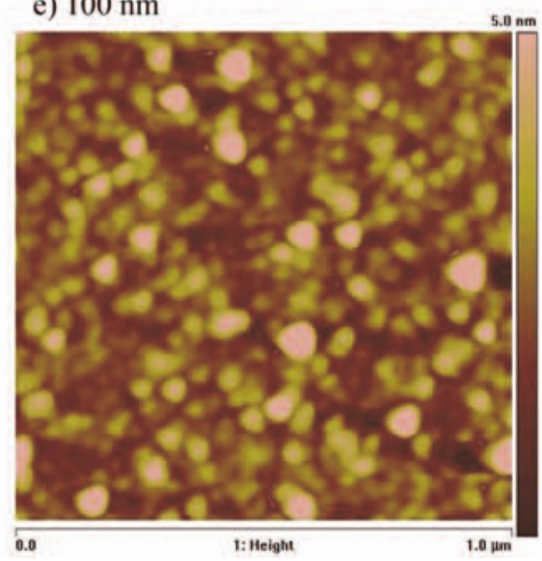

Figure 3 (online color at: www.pss-a.com) $1 \mu \mathrm{m} \times 1 \mu \mathrm{m}$ AFM images in tapping mode of the (a) $10 \mathrm{~nm}$ thick; (b) $20 \mathrm{~nm}$ thick; (c) $60 \mathrm{~nm}$ thick; (d) $75 \mathrm{~nm}$ thick; (e) $100 \mathrm{~nm}$ thick LSMO films on STO/Si. 


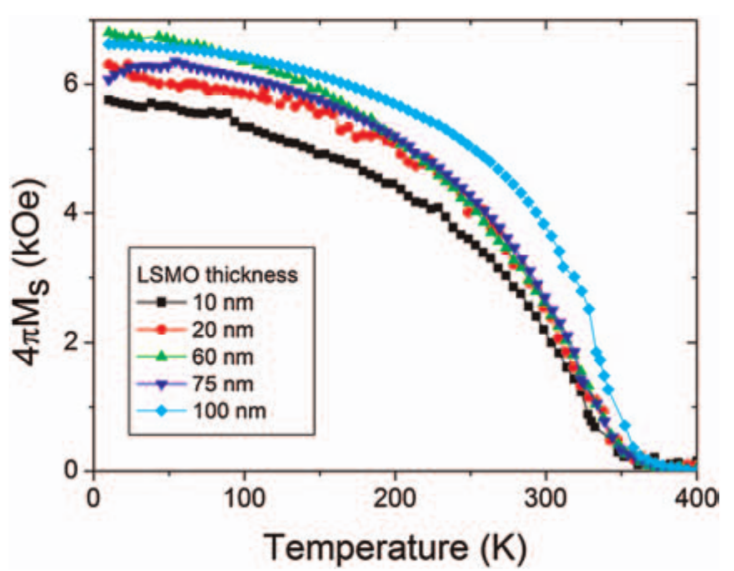

Figure 4 (online color at: www.pss-a.com) Temperature dependence of the saturated magnetization $\left(4 \pi M_{\mathrm{s}}\right)$ of the $10-100 \mathrm{~nm}$ thick $\mathrm{LSMO} / \mathrm{STO} / \mathrm{Si}$ films at an in-plane applied magnetic field of $5 \mathrm{kOe}$.

magnetometer in the $10-400 \mathrm{~K}$ range. Figure 4 shows the saturated magnetization versus temperature behavior under an in-plane applied magnetic field of $5 \mathrm{kOe}$. The magnetization shows a sharp transition behavior. All curves have been fitted by a theoretical standard static Brillouin magnetization function. The Curie temperature $T_{\mathrm{C}}$ estimated by this fitting is within the range $320-345 \mathrm{~K}$ (see Table 1) for all films and is in good agreement with the bulk theoretical values $\left(T_{\mathrm{C}} \approx 350 \mathrm{~K}\right)$. Saturated magnetization values at low temperature $(T=10 \mathrm{~K})$ lies in between 5800 and $6900 \mathrm{Oe}$ for all samples, which is close to the expected bulk value of 7350 Oe. The good agreement between theoretical and experimental values is slightly decreasing for thinner films, as frequently reported $[10,28]$.

A remarkable point in the case of our series of samples is that all samples, even the thinnest ones, show saturation magnetization and Curie temperature values close to the theoretical ones. In the $10 \mathrm{~nm}$ LSMO, the magnetization value at room temperature $(T=294 \mathrm{~K})$ is $42 \%$ of the saturated magnetization value at very low temperature $(T=10 \mathrm{~K})$ while in the $100 \mathrm{~nm}$ thick film, the magnetization value at room temperature is only $60 \%$ of the saturated magnetization at low temperature. These results are again comparable to those achieved for LSMO films directly grown on single crystal STO substrates [29] and arise hopes for room temperature applications. Further static and dynamic magnetic characterizations of the 20 and $60 \mathrm{~nm}$ thick LSMO films on STO/Si can be found elsewhere [30].

Electrical transport measurements were performed by the standard four-probe technique as a function of temperature on unpatterned films. Figure 5 shows the electrical resistivity versus temperature curves measured on the $10-100 \mathrm{~nm}$ thick LSMO films. The measured electrical resistivity values were in the $1.4 \times 10^{-5}-3.8 \times 10^{-5} \Omega \mathrm{m}$ range at $300 \mathrm{~K}$ for all the LSMO thicknesses (see Table 1), which is very close to the bulk value [27]. All films showed a metal-insulating transition temperature $T_{\mathrm{MI}}$ in the $350-380 \mathrm{~K}$ range.

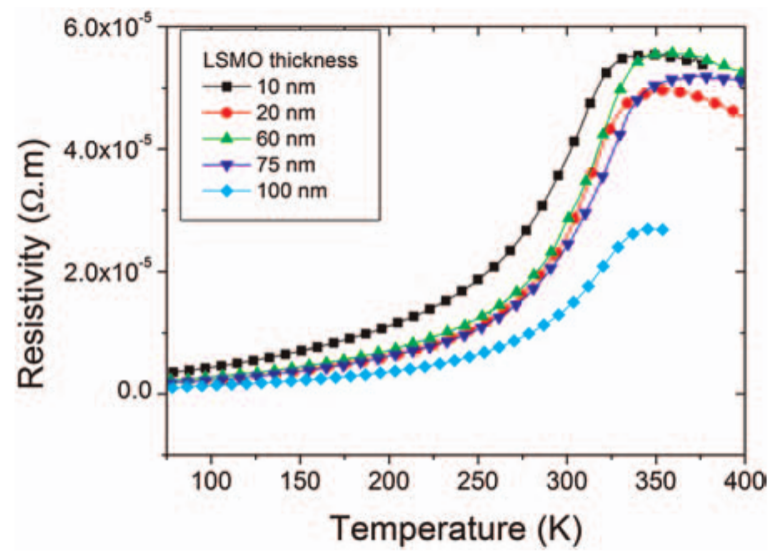

Figure 5 (online color at: www.pss-a.com) Electrical resistivity versus temperature characteristics of the 10-100 nm thick LSMO/ STO/Si films.

4 Electrical low frequency noise measurements For electrical low frequency noise measurements, a $200 \mathrm{~nm}$ thick gold layer was ion beam sputtered on the LSMO/STO/ Si heterostructures in order to make low resistive electrical connections. The LSMO thin films were patterned by UV photolithography and argon ion etching to form $50 \mu \mathrm{m}$ wide and $150 \mu \mathrm{m}$ long bridges. Each structure includes two gold pads for supplying the current and two gold pads carrying out the voltage measurements in order to form four probe connections. The connections between the external circuitry and the patterned films with gold contact pads were made using a four-probe system. The electronics readout mainly consists of a low noise high output impedance DC current source [31] and a dedicated low noise instrumentation amplifier with a voltage gain of about 1000 , a $1 \mathrm{~Hz}-100 \mathrm{kHz}$ bandwidth, an input voltage white noise of $20 \times 10^{-18} \mathrm{~V}^{2} / \mathrm{Hz}$, and negligible input current noise. A spectrum analyzer (Agilent 89410A) calculates the noise spectral density for frequencies in the $1 \mathrm{~Hz}-100 \mathrm{kHz}$ range.

Low frequency noise comes from various origins that lead to different frequency dependences. As shown in Fig. 6 for the case of the $20 \mathrm{~nm}$ thick LSMO/STO/Si film, we could clearly observe two types of noise in all our samples: Johnson (or thermal) noise, and $1 / f$ (or flicker) noise. The first one depends neither on the bias current nor on the frequency. It is due to spontaneous fluctuations induced by thermal excitations and it is related to the electrical resistance $R$ of the sample (the voltage noise spectral density is given by the Nyquist formula $4 k_{\mathrm{B}} T R$, where $k_{\mathrm{B}}$ is the Boltzmann constant and $T$ the temperature). The second one is a frequencydependent component in $1 / f^{\gamma}$, showing a parameter $\gamma$ close to -1 , which gives the name of " $1 / f$ ". This $1 / f$ noise is usually described by the Hooge empirical relation, which does not have any physical basis but has been shown to agree well with experimental observations for electrically homogeneous samples. This relation is given by the following 


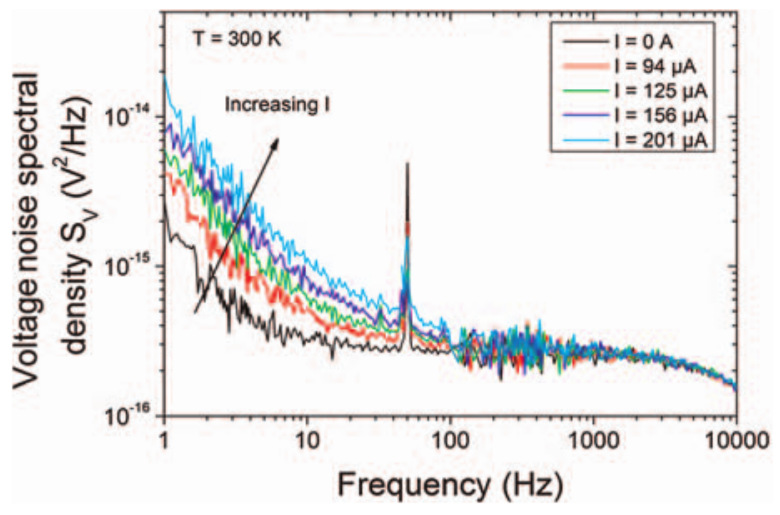

Figure 6 (online color at: www.pss-a.com) Voltage noise spectral density $S_{\mathrm{V}}$ spectra measured at $300 \mathrm{~K}$ on the $20 \mathrm{~nm}$ thick LSMO/ $\mathrm{STO} / \mathrm{Si}$ film patterned as a $50 \mu \mathrm{m}$ wide $150 \mu \mathrm{m}$ long bridge for different bias current $I$.

general formula [23]:

$$
\frac{S_{\mathrm{V}}}{V^{2}}=\frac{\alpha_{\mathrm{H}}}{n} \times \frac{1}{\Omega \times f^{\gamma}},
$$

where $S_{\mathrm{V}}$ is the voltage noise spectral density $\left(\mathrm{V}^{2} / \mathrm{Hz}\right), V$ the sample voltage $(\mathrm{V}), \alpha_{\mathrm{H}}$ the Hooge parameter (dimensionless), $n$ the charge carrier density $\left(\mathrm{m}^{-3}\right), \Omega$ the sample volume $\left(\mathrm{m}^{3}\right)$, and $f$ is the measuring frequency $(\mathrm{Hz})$. It is very useful to compare the $1 / f$ noise magnitude in different materials independently of the sample volume and the bias conditions. In order to estimate the voltage noise spectral density of the material, the noise of the electronic readout and the noise of the voltage contacts were removed. As presented in Fig. 7, the quadratic dependence of $S_{\mathrm{V}}$ versus $V$ expected from Eq. (1) was verified within experimental error bars for all samples at $300 \mathrm{~K}$, thus enabling a correct estimation of $\alpha_{\mathrm{H}} / n$ values.

As reported in Table 1, normalized Hooge parameters $\alpha_{\mathrm{H}} / n$ in the $(0.95 \pm 0.25) \times 10^{-30}-(3.41 \pm 0.71) \times 10^{-30} \mathrm{~m}^{3}$

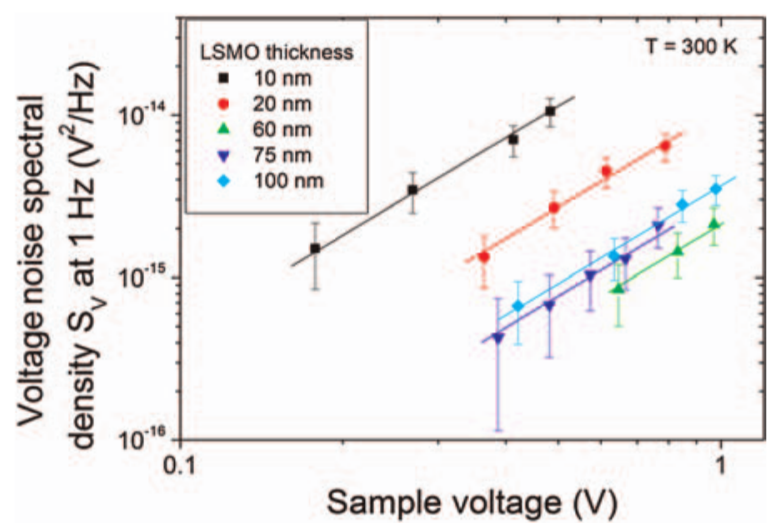

Figure 7 (online color at: www.pss-a.com) Voltage noise spectral density $S_{\mathrm{V}}$ at $1 \mathrm{~Hz}$ and $300 \mathrm{~K}$ versus voltage across the $50 \mu \mathrm{m}$ wide $150 \mu \mathrm{m}$ long bridges for all of the 10-100 nm thick LSMO/STO/Si films. Error bars and fitted curves showing the quadratic dependence of $S_{\mathrm{V}}$ versus $V$ are added to the measured data. range were measured at $300 \mathrm{~K}$, which are comparable to the noise level typically measured in the best LSMO films on STO single crystal substrates with $\alpha_{\mathrm{H}} / n$ values of $0.8 \times 10^{-30} \mathrm{~m}^{3}[32-34]$.

5 Conclusions In summary, we grew epitaxial LSMO thin films with thicknesses ranging from 10 to $100 \mathrm{~nm}$ on STO buffered (001) Si substrates. The samples show very low noise. The FWHM of the LSMO 002 rocking curves were about $0.2^{\circ}-0.3^{\circ}$. AFM measurements confirmed that the film surfaces were smooth (RMS roughness of $0.5 \mathrm{~nm}$ for 10-75 nm LSMO thicknesses). The films showed electrical and magnetic properties comparable to those of LSMO grown on (001) STO single crystals. Low frequency noise measurements were performed at $300 \mathrm{~K}$. Normalized Hooge parameters were measured in the $(0.95 \pm 0.25) \times 10^{-30}$ $(3.41 \pm 0.71) \times 10^{-30} \mathrm{~m}^{3}$ range, demonstrating their potential use in innovative applications based on LSMO thin films grown on silicon substrates operating at room temperature.

Acknowledgements Work at Cornell was supported by AFOSR through Award No. FA9550-10-1-0524. The authors wish to thank B. Leridon and P. Monod at ESPCI for the use of the SQUID magnetometer.

\section{References}

[1] R. E. Cohen, Nature 358, 136 (1998).

[2] M. Dawber, K. M. Rabe, and J. F. Scott, Rev. Mod. Phys. 77, 1083 (2005).

[3] J. Heremans, J. Phys. D 26, 1149 (1993).

[4] S. Jin, M. McCormack, T. H. Tiefel, and R. Ramesh, J. Appl. Phys. 76, 6929 (1994).

[5] L. Méchin, G. Huot, and D. Bloyet, Appl. Phys. Lett. 85(15), 3154 (2004).

[6] Z. Trajanovic, C. Kwon, M. C. Robson, K.-C. Kim, M. Rajeswari, R. Ramesh, T. Venkatesan, S. E. Lofland, S. M. Bhagat, and D. Fork, Appl. Phys. Lett. 69, 1005 (1996).

[7] I. Bergenti, V. Dediu, E. Arisi, M. Cavallini, F. Biscarini, C. Taliani, M. P. de Jong, C. L. Dennis, J. F. Gregg, M. Solzi, and M. Natali, J. Magn. Magn. Mater. 312, 453 (2007).

[8] J.-H. Kim, S. I. Khartsev, and A. M. Grishin, Appl. Phys. Lett. 82(24), 4295 (2003).

[9] L. Méchin, P. Perna, C. Barone, J.-M. Routoure, and Ch. Simon, Mater. Sci. Eng. B 144, 73 (2007).

[10] A. K. Pradhan, D. Hunter, T. Williams, B. Lasley-Hunter, R. Bah, H. Mustafa, R. Rakhimov, J. Zhang, D. J. Sellmyer, E. E. Carpenter, D. R. Sahu, and J.-L. Huang, J. Appl. Phys. 103, 023914 (2008).

[11] P. Perna, L. Méchin, M. P. Chauvat, P. Ruterana, Ch. Simon, and U. Scotti di Uccio, J. Phys.: Condens. Matter 21, 306005 (2009).

[12] R. A. McKee, F. J. Walker, and M. F. Chisholm, Phys. Rev. Lett. 81, 3014 (1998).

[13] J. H. Hao, J. Gao, Z. Wang, and D. P. Wu, Appl. Phys. Lett. 87, 131908 (2005). 
[14] G. Delhaye, C. Merckling, M. El-Kazzi, G. Saint-Girons, M. Gendry, Y. Robach, G. Hollinger, L. Largeau, and G. Patriarche, J. Appl. Phys. 100, 124109 (2006).

[15] L. V. Goncharova, D. G. Starodub, E. Garfunkel, T. Gustafsson, V. Vaithyanathan, J. Lettieri, and D. G. Schlom, J. Appl. Phys. 100, 014912 (2006).

[16] Z. Luo, J. H. Hao, and J. Gao, Appl. Phys. Lett. 91, 062105 (2007).

[17] X. Y. Zhou, J. Miao, J. Y. Dai, H. L. W. Chan, C. L. Choy, and Y. Wang, Appl. Phys. Lett. 90, 012902 (2007).

[18] M. P. Warusawithana, C. Cen, C. R. Sleasman, J. C. Woicik, Y. Li, L. F. Kourkoutis, J. A. Klug, H. Li, P. Ryan, L.-P. Wang, M. Bedzyk, D. A. Muller, L.-Q. Chen, J. Levy, and D. G. Schlom, Science 324, 367 (2009).

[19] H. Li, X. Hu, Y. Wei, Z. Yu, X. Zhang, R. Droopad, A. A. Demkov, J. Edwards, Jr., K. Moore, W. Ooms, J. Kulik, and P. Fejes, J. Appl. Phys. 93, 4521 (2003).

[20] D. H. Wang, L. Yan, C. K. Ong, and Y. W. Du, Appl. Phys. Lett. 89, 182905 (2006).

[21] T. Uemura, K. Sekine, K.-I. Matsuda, and M. Yamamoto, Jpn. J. Appl. Phys. 44, 2604 (2005).

[22] A. K. Pradhan, S. Mohanty, K. Zhang, J. B. Dadson, E. M. Jackson, D. Hunter, R. R. Rakhimov, and G. B. Loutts, Appl. Phys. Lett. 86, 012503 (2005).

[23] F. N. Hooge, T. G. M. Kleinpenning, and L. K. J. Vandamme, Rep. Prog. Phys. 44, 481 (1981).
[24] F. N. Hooge, Phys. Lett. 29A(3), 139 (1969).

[25] C. Adamo, X. Ke, H. Q. Wang, H. L. Xin, T. Heeg, M. E. Hawley, W. Zander, J. Schubert, P. Schiffer, D. A. Muller, L. Maritato, and D. G. Schlom, Appl. Phys. Lett. 95, 112504 (2009).

[26] D. Hunter, J. B. Dadson, K. Zhang, B. Lasley, K. Lord, S. Mohanty, T. M. Williams, R. R. Rakhimov, A. K. Pradhan, J. Zhang, and D. J. Sellmyer, J. Appl. Phys. 99, 08Q307 (2006).

[27] A. Urushibara, Y. Moritomo, T. Arima, A. Asamitsu, G. Kido, and Y. Tokura, Phys. Rev. B 51, 14103 (1995).

[28] K. Steenbeck, T. Habisreuther, C. Dubourdieu, and J. P. Sénateur, Appl. Phys. Lett. 80, 3361, (2002).

[29] S. Jin, T. H. Tiefel, M. McCormack, R. A. Fastnacht, R. Ramesh, and L. H. Chen, Science 264, 413 (1994).

[30] M. Belmeguenai, S. Mercone, C. Adamo, L. Méchin, C. Fur, P. Monod, P. Moch, and D. G. Schlom, Phys. Rev. B 81, 054410 (2010).

[31] J.-M. Routoure, D. Fadil, S. Flament, and L. Méchin, AIP Conf. Proc. 922, 419 (2007).

[32] L. Méchin, J. M. Routoure, B. Guillet, F. Yang, S. Flament, D. Robbes, and R. A. Chakalov, Appl. Phys. Lett. 87, 204103 (2005).

[33] F. Yang, L. Méchin, J.-M. Routoure, B. Guillet, and R. A. Chakalov, J. Appl. Phys. 99, 024903 (2006).

[34] L. Méchin, J.-M. Routoure, S. Mercone, F. Yang, S. Flament, and R. A. Chakalov, J. Appl. Phys. 103, 083709 (2008). 